\title{
Comunicação \\ Uso da rapadura como meio nutritivo para cultivo in vitro de bananeira cv. Maçã
}

\author{
Juliana Martins Ribeiro ${ }^{1}$, Natoniel Franklin de Melo $^{1}$, Angela Katiussia Nascimento dos Santos Coelho ${ }^{2}$, \\ Márcio dos Santos Teixeira Pinto
}

\begin{abstract}
RESUMO
O objetivo deste estudo foi avaliar o efeito da rapadura sobre o desenvolvimento, in vitro, de bananeira, cv. Maçã, visando à redução de custos de produção, por cultura de tecidos. Explantes de bananeira foram inoculados em meios nutritivos, formulados à base de rapadura, com quatro concentrações distintas $(10,25,50$ e $75 \%$ de solução de rapadura), e os dados obtidos foram comparados com aqueles das plantas cultivadas em meio MS $100 \%$ (controle), perfazendo um total de cinco tratamentos. Ao final de 60 dias, foram avaliados os números médios de folhas, brotos e raízes, bem como os números médios de explantes mortos e oxidados. Não houve diferença significativa entre os tratamentos para a maior parte dos parâmetros avaliados, exceto para o número médio de explantes oxidados, que foi maior no tratamento com $75 \%$ de rapadura. Concluiu-se que meios nutritivos com até 50\% de rapadura em sua composição, sem reguladores vegetais, podem ser utilizados em substituição ao meio MS para o cultivo in vitro de bananeira.
\end{abstract}

Palavras-chave: micropropagação, Musa spp., meio de cultura.

\begin{abstract}
Use of panela as nutritive medium for in vitro culture of banana cv. Maçã

The purpose of this study was to evaluate the effect of panela (hard brown sugar) on in vitro development of banana cv. Maçã, in order to reduce production costs. Banana explants were inoculated in nutrient media formulated with four different concentrations of panela solution (10,25, 50 and 75\%) and data were compared with those of plants grown on MS medium (control), totalizing five treatments. After 60 days, the average number of leaves, shoots and roots, as well as the mean number of explants dead and oxidized were analyzed. There was no significant difference between treatments for most parameters, except for the mean number of oxidized explants, which was higher in the treatment containing $75 \%$ of panela. It was concluded that nutrient media with up to $50 \%$ of panela in the composition, without plant growth regulators, can be used for in vitro banana replacing the MS media.
\end{abstract}

Key words: micropropagation, Musa spp., nutritive media.

Recebido para publicação em 05/10/2012 e aprovado em 19/04/2013.

${ }^{1}$ Biólogos, Doutores. Laboratório de Biotecnologia Vegetal, Embrapa Semiárido, Rodovia BR 428, Km 152, Caixa Postal 23, Zona Rural, 56302-970, Petrolina, Pernambuco, Brasil. juliana.ribeiro@cpatsa.embrapa.br (autora correspondente); natoniel@cpatsa.embrapa.br

${ }^{2}$ Licenciada em Ciências. Laboratório de Biotecnologia Vegetal, Embrapa Semiárido, Rodovia BR 428, Km 152, Caixa Postal 23, Zona Rural, 56302-970, Petrolina, Pernambuco, Brasil. angela@cpatsa.embrapa.br

${ }^{3}$ Biólogo, Doutor. Biociências e Biotecnologia, Rua U, 08, Parque Prazeres,

28013-602, Campos dos Goytacazes, Rio de Janeiro, Brasil. marciostp@yahoo.com.br

Rev. Ceres, Viçosa, v. 60, n.5, p. 722-725, set/out, 2013 


\section{INTRODUÇÃO}

A micropropagação, para a produção de mudas de bananeira, viabiliza a obtenção de considerável número de plantas, em curto espaço de tempo, livres de pragas e doenças. Proporciona uniformidade de desenvolvimento e da colheita, no primeiro ciclo da cultura e, além de serem mais produtivas no primeiro ciclo, as plantas apresentam maior precocidade, florescendo até quatro meses antes das plantas convencionais (Álvares \& Caldas, 2002).

Mesmo sendo uma tecnologia com várias vantagens, a produção de mudas in vitro ainda apresenta um custo de produção elevado. Algumas características são consideradas importantes para tornar uma biofábrica mais econômica tais como: a utilização da luz natural em salas de crescimento (Ponce et al., 2000) e a substituição de reagentes para análise (PA) no preparo dos meios nutritivos (Bernardi et al., 2004; Ribeiro \& Teixeira, 2008). Kodym \& Zapata (2001) afirmam que a combinação de ambas as técnicas pode levar a uma redução no custo de produção de até $90 \%$, em laboratório de produção de mudas.

O preparo de meios nutritivos, utilizando-se reagentes PA, deve-se ao fato de estes conterem quantidades reduzidas de impurezas, minimizando-se possíveis influências negativas de outras substâncias químicas, nas reações das plantas cultivadas. Entretanto, para a produção comercial de plantas em laboratórios, esse grau de pureza não é necessário (Prakash et al. 2004), desde que sejam adotadas técnicas eficientes de esterilização. Meios nutritivos alternativos, preparados a partir de derivados do processamento da cana-de-açúcar, já foram descritos na literatura, apresentando resultados satisfatórios para o cultivo in vitro de diferentes espécies de plantas (Dhamankar, 1992; Santana et al., 2009; Buah et al., 2011; Ribeiro et al., 2012).

A rapadura é conhecida pelo seu alto valor calórico, sendo rica também em vitaminas, minerais e proteínas, é considerada uma fonte de nutrientes e, consequentemente, promissora para utilização como meio nutritivo alternativo para cultivo in vitro. Baseado nestas informações, objetivou-se, com este trabalho, avaliar o efeito da rapadura sobre o desenvolvimento in vitro de bananeira cv. Maçã.

\section{MATERIAL E MÉTODOS}

Os explantes utilizados neste experimento foram provenientes de culturas estoque de bananeira, cv. Maçã, mantidas em sala de crescimento do Laboratório de Biotecnologia da Embrapa Semiárido, sob subcultivos de 60 dias, fotoperíodo de 16 horas, temperatura variando entre 23 e $27^{\circ} \mathrm{C}$ e intensidade luminosa de $40 \mu \mathrm{mol} \mathrm{m} \mathrm{m}^{2}$. O meio de cultura utilizado para a manutenção da cultura estoque foi preparado de acor- do com a formulação de sais inorgânicos e vitaminas, encontrados no meio MS (Murashige \& Skoog, 1962), 100 $\mathrm{mg} \mathrm{L}^{-1}$ de inositol, 6,5 $\mathrm{g} \mathrm{L}^{-1}$ de agar, $30 \mathrm{~g} \mathrm{~L}^{-1}$ de sacarose, 2,5 $\mathrm{mg} \mathrm{L}^{-1}$ de benzilaminopurina (BAP), $\mathrm{pH} 5,9$ e esterilizado por autoclavagem $\left(121{ }^{\circ} \mathrm{C}\right.$, por 20 minutos $)$.

No interior da capela de fluxo laminar, e, com a utilização de vidrarias e utensílios esterilizados, plantas com aproximadamente $1 \mathrm{~cm}$, provenientes da cultura estoque citada, foram transferidas para placa de Petri, as brotações foram separadas e delas retiradas todas as folhas e raízes. Os explantes foram transferidos para tubos de ensaio de 25 x $150 \mathrm{~mm}$, contendo $20 \mathrm{~mL}$ de meio nutritivo, preparado conforme as especificações abaixo.

Primeiramente, foi preparada uma solução de rapadura a $3 \%$, para a qual seis gramas de rapadura foram dissolvidos em $200 \mathrm{~mL}$ de água destilada. Esse valor foi calculado, partindo-se do princípio de uma concentração de $100 \%$ para a rapadura sólida, bem como da percentagem de sacarose utilizada no preparo do meio MS. A partir dessa solução, foram preparados os seguintes tratamentos: T1: $100 \%$ meio MS (200 mL de meio) - controle preparado segundo Murashige \& Skoog (1962); T2: 90\% MS (180 $\mathrm{mL}$ de meio $)+10 \%$ solução de rapadura $(20 \mathrm{~mL}$ de solução de rapadura a 3\%); T3: $75 \%$ meio MS (150 mL de meio $)+25 \%$ solução de rapadura $(50 \mathrm{~mL}$ de solução de rapadura a 3\%), T4: $50 \%$ meio $\mathrm{MS}(100 \mathrm{~mL}$ de meio $)+50 \%$ solução de rapadura $(100 \mathrm{~mL}$ de solução de rapadura a 3\%) e T5: $25 \%$ meio MS (50 mL de meio) $+75 \%$ solução de rapadura ( $150 \mathrm{~mL}$ de solução de rapadura a $3 \%)$. Não foram adicionados reguladores vegetais em nenhum dos tratamentos citados. $\mathrm{O} \mathrm{pH}$ de todos os tratamentos foi aferido para 5,9 e os meios nutritivos foram esterilizados por autoclavagem $\left(121^{\circ} \mathrm{C}\right.$, por 20 minutos).

Após sessenta dias de cultivo, em sala de crescimento com as condições supracitadas, foram tomados dados quanto ao número médio de folhas, brotos e raízes, bem como ao número médio de explantes mortos e oxidados. $\mathrm{O}$ experimento foi conduzido em delineamento inteiramente casualizado, com cinco tratamentos, cinco repetições e a unidade experimental composta de quatro tubos de ensaio. Foi realizada a análise de variância e as médias foram comparadas pelo Teste de Tukey, a 5\% de probabilidade.

\section{RESULTADOS E DISCUSSÃO}

Na Tabela 1, estão apresentados os dados obtidos após a análise de variância dos números médios de folhas, de brotos e de raízes e dos números médios de explantes mortos e oxidados, obtidos nos diferentes tratamentos testados. Verifica-se diferença estatística apenas para a variável número médio de explantes oxidados.

De acordo com os resultados da Tabela 2, os números médios de brotos, de folhas e de raízes foram estatistica- 
Tabela 1. Análise de variância dos parâmetros analisados nos diferentes tratamentos. Números médios de folhas (NMF), brotos (NMB), raízes (NMR) e números médios de explantes mortos (NMEM) e oxidados (NMEO). Embrapa Semiárido, Petrolina - PE, 2012

\begin{tabular}{|c|c|c|c|c|c|c|c|c|c|c|c|}
\hline \multirow{2}{*}{ FV } & \multirow{2}{*}{ GL } & \multicolumn{2}{|c|}{ NMF } & \multicolumn{2}{|c|}{ NMB } & \multicolumn{2}{|c|}{ NMR } & \multicolumn{2}{|c|}{ NMEM } & \multicolumn{2}{|c|}{ NMEO } \\
\hline & & QM & $\mathbf{F}$ & QM & $\mathbf{F}$ & QM & $\mathbf{F}$ & QM & $\mathbf{F}$ & QM & $\mathbf{F}$ \\
\hline Tratamento & 4 & 0,92 & $1,23^{\mathrm{NS}}$ & 0,89 & $1,12^{\mathrm{NS}}$ & 1,66 & $2,59^{\mathrm{NS}}$ & 0,02 & $0,5^{\mathrm{NS}}$ & 0,26 & $13 *$ \\
\hline Resíduo & 20 & 0,75 & & 0,79 & & 0,64 & & 0,04 & & 0,02 & \\
\hline Total & 24 & & & & & & & & & & \\
\hline
\end{tabular}

* Significativo a $5 \%$ de probabilidade

Ns Não significativo a $5 \%$ de probabilidade

Tabela 2. Números médios de folhas (NMF), brotos (NMB), raízes (NMR) e números médios de explantes mortos (NMEM) e oxidados (NMEO) em função dos diferentes tratamentos. Embrapa Semiárido, Petrolina - PE, 2012

\begin{tabular}{|c|c|c|c|c|c|}
\hline Tratamentos & NMF & NMB & NMR & NMEM & NMEO \\
\hline T1 (controle) & $1,05 \mathrm{a}$ & $1,1 \mathrm{a}$ & $0,8 \mathrm{a}$ & $0,1 \mathrm{a}$ & $0,05 \mathrm{~b}$ \\
\hline $\mathrm{T} 2$ & $1,73 \mathrm{a}$ & $1,1 \mathrm{a}$ & $1,37 \mathrm{a}$ & $0,2 \mathrm{a}$ & $0 \mathrm{~b}$ \\
\hline $\mathrm{T} 3$ & $2,07 \mathrm{a}$ & $0,2 \mathrm{a}$ & $2,1 \mathrm{a}$ & $0,25 \mathrm{a}$ & $0,05 \mathrm{~b}$ \\
\hline $\mathrm{T} 4$ & $2,01 \mathrm{a}$ & $0,85 \mathrm{a}$ & $1,97 \mathrm{a}$ & $0,2 \mathrm{a}$ & $0,05 \mathrm{~b}$ \\
\hline $\mathrm{T} 5$ & $1,30 \mathrm{a}$ & $0,35 \mathrm{a}$ & $1,0 \mathrm{a}$ & $0,1 \mathrm{a}$ & $0,55 \mathrm{a}$ \\
\hline
\end{tabular}

Dados acompanhados de uma mesma letra são iguais segundo o teste de Tukey com $5 \%$ de probabilidade.

mente iguais, entre os tratamentos com meios nutritivos formulados à base de rapadura e o meio MS. Observa-se, entretanto, que o número médio de explantes oxidados foi maior no tratamento composto por meio de cultura com $75 \%$ de rapadura.

Alguns derivados do processamento da cana-de-açúcar possuem um alto valor nutricional, já tendo sido a sua utilização como componente de meios nutritivos para cultivos in vitro citada na literatura. Dhamankar (1992) utilizou melado de cana-de-açúcar como meio nutritivo para o cultivo de cana-de-açúcar e conseguiu resultados satisfatórios na indução de calos e brotos. Santana et al. (2009) utilizaram melado de cana-de-açúcar, como fonte de carboidrato e vitaminas, para o cultivo in vitro de mandioca, e observaram que os números médios de folhas e de raízes e a biomassa das matérias seca e fresca das plantas cultivadas em meio com melado de cana-de-açúcar não diferiram daqueles do grupo controle, corroborando os resultados obtidos neste trabalho.

Buah et al., (2011) estudaram o efeito do caldo de cana-de-açúcar sobre o desenvolvimento in vitro de bananeiras e observaram que os maiores valores de número médio de brotos e de biomassa fresca ocorreram nos tratamentos com sacarose e com 5\% de caldo de canade-açúcar. Esses resultados estão de acordo com aqueles obtidos neste estudo. Ribeiro et al. (2012) avaliaram o efeito do melado de cana-de-açúcar sobre o desenvolvimento in vitro de bananeira 'Maçã' e observaram que, embora o meio nutritivo à base de melado não tenha favorecido o desenvolvimento de plantas com maiores números de folhas, quando comparados com o meio MS, não houve diferença significativa para o número médio de raízes, entre eles.
Quanto à oxidação dos explantes, geralmente ocorre em função da liberação de compostos fenólicos pelos tecidos vegetais (Ledo et al., 2002). Considerandose que a rapadura possui em sua composição uma elevada concentração de compostos fenólicos (Olbrich, 2006; Takara et al., 2007), o aumento da oxidação dos explantes, observado no tratamento com meios nutritivos compostos por $75 \%$ de rapadura, pode ser devido ao aumento da concentração destes compostos em meios nutritivos com rapadura em concentrações mais elevadas, corroborando os resultados obtidos por Ribeiro et al., (2012).

\section{CONCLUSÃO}

Meios nutritivos com até $50 \%$ de rapadura em sua composição podem ser utilizados, em substituição ao meio MS, para o cultivo in vitro de bananeira.

\section{AGRADECIMENTOS}

À Fundação de Amparo à Ciência e Tecnologia do Estado de Pernambuco (FACEPE) e à Embrapa Semiárido, pelo suporte financeiro.

\section{REFERÊNCIAS}

Álvares MC \& Caldas LS (2002) Crescimento, produção e variação somaclonal em bananeiras micropropagadas. Pesquisa Agropecuária Brasileira, 37:415-420.

Bernardi WF, Rodrigues BI, Neto PC, Ando A, Neto AT, Ceravolo LC \& Montes SMNM (2004) Micropropagação de baixo custo em bananeira cv. Maçã em meios com diferentes fontes de carbono e avaliação da performance em campo das mudas produzidas. Revista Brasileira de Fruticultura, 26:503-506. 
Buah JN, Tachie-Menson JW, Addae G \& Asarev P (2011) Sugarcane Juice as an Alternative Carbon Source for in vitro Culture of Plantains and Bananas. American Journal of Food Technology, 6:685-694.

Dhamankar VS (1992) Molasses, a source of nutrients for in vitro sugar cane culture. Sugar Cane, 4:14-15.

Kodym A \& Zapata FJA (2001) Low-cost alternatives for the micropropagation of banana. Plant Cell Tissue and Organ Culture, 66:67-71.

Ledo AS, Lameira AO \& Benbadis A (2002) Explantes de cupuaçuzeiro submetidos a diferentes condições de cultura in vitro. Revista Brasileira de Fruticultura, 24:604-607.

Murashige T \& Skoog F (1962) A revised medium for rapid growth and bioassays with tobacco tissue cultures. Physiologia Plantarum, 15:473-497.

Olbrich H (2006) The mosasses. Berlin, Biotechnology-Kempe Gmb. $131 \mathrm{p}$

Ponce JNP, Castellá MS \& Pérez PO (2000) Possibilidades y potencial de la propagación masiva de plantas en Cuba. In: Instituto de Biotecnología de las Plantas (ed.) Biotecnología Vegetal. Cuba, Villa Clara, 1:3-12.
Prakash S, Hoque MI \& Brinks T (2004) Culture media and containers. In: Technical Meeting Of Low Costs Options For Tissue Culture Technology In Developing Countries, 2002, Viena. Proceedings, IAEA: FAO. p.29-40.

Ribeiro JM \& Teixeira SL (2008) Substituição de nitrato de potássio (PA) por salitre potássico no preparo de meio de cultura de tecidos vegetais esterilizado com hipoclorito de sódio. Ciência e Agrotecnologia, 32:1209-1213.

Ribeiro JM, Melo NF, Coelho AKNS \& Pinto MST (2012) Efeito do melado de cana-de-açúcar no desenvolvimento in vitro de bananeira (Musa spp.) cv. Maçã. Revista Ceres, 59:293-298.

Santana, MA, Romay G, Matehus J, Vicente-Villardón JL \& Demey JR (2009) A simple and low-cost strategy for micropropagation of cassava (Manihot esculenta Crantz). African Journal of Biotechnology, 8:3789-3897.

Takara K, Ushijima K, Wada K, Iwasaki H \& Yamashita M (2007) Phenolic compounds from sugar cane molasses possessing antibacterial activity against cariogenic bacteria. Journal of Oleo Science, 56:611-614. 